\title{
Detection of subclinical pregnancy toxemia and evaluation of glycaemic status in Malabari does
}

\author{
P. Shonima1, Murad Alsawalha' ${ }^{2}$ C. Aswathy ${ }^{1}$, M. Rosemol Jacob', \\ K. K. Jayavardhanan ${ }^{1}$, K. Aiswarya K' ${ }^{1}$ V. Vishnu Priya ${ }^{3}$, \\ Surapaneni Krishna Mohan ${ }^{4}$
}

\begin{abstract}
${ }^{1}$ Department of Veterinary Biochemistry, College of Veterinary and Animal Sciences, Kerala Veterinary and Animal Sciences University, Thrissur, Kerala, India, ${ }^{2}$ Department of Chemical and Process Engineering Technology, Jubail Industrial College (JIC), P.O. Box 10099, Jubail Industrial, 31961, Kingdom of Saudi Arabia, ${ }^{3}$ Department of Biochemistry, Saveetha Dental College and Hospitals, Saveetha Institute of Medical and Technical Sciences (SIMATS), Saveetha University, Chennai, Tamil Nadu, India, ${ }^{4}$ Department of Biochemistry, Chettinad Hospital and Research Institute, Chettinad Academy of Research and Education (CARE), Chettinad University, Chennai, Tamil Nadu, India
\end{abstract}

\begin{abstract}
Aim: The aim of the study was to screen Malabari does for subclinical pregnancy toxemia and to evaluate their glycaemic status. Materials and Methods: This study consist of 4 groups; Group I early pregnant does $(n=7)$, Group II late pregnant does with one fetus $(n=6)$, Group III late pregnant does with two fetuses $(n=8)$, and Group IV nonpregnant does $(n=8)$. The pregnancy was confirmed by 3.5 Megahertz B-mode ultrasonography. The concentration of beta-hydroxybutyrate (BHB) and glucose was analyzed in the blood samples. Results and Discussion: Significant increase in serum BHB concentration was found in Groups I and II when compared to control group. Group III showed highly significant increase when compared to control group. Among the four groups selected, late pregnant animals with two fetuses had a BHB level of $0.81 \pm 0.10 \mathrm{mmol} / \mathrm{l}$, which shows that those animals were in subclinical pregnancy toxemic stage. A highly significant decrease in plasma glucose concentration was found in Group I, Group II, and Group III; compared to controls. Hypoglycemia was seen in all the three groups studied. Conclusion: Hyperketonemia not only represents a disease sign but rather acts in a multifunctional way in promoting development of pregnancy toxemia.
\end{abstract}

Key words: Beta-hydroxybutyrate, Malabari does, pregnancy toxemia

\section{INTRODUCTION}

I ndiaranks second in the world goatpopulation with $14.6 \%$ of the population. Goat farming is the main means of livelihood for a large sector of Indian population especially in rural areas and their contribution to Indian rural economy is honorable. Of the 23 native breeds of goats in India, goat production in Kerala is mainly centered on its native breed, Malabari, which is reputed for its high prolificacy, milk yield, excellent growth rate, and adaptability to the hot humid conditions prevalent in the state. ${ }^{[1]}$ The breed is widely distributed in Kasargod, Thrissur, Kannur, and Malappuram district of northern Kerala and mainly concentrated in and around Tellicherry and, hence, is also popularly known as Tellicherry. Pregnancy toxemia is a metabolic disorder of pregnant does which occurs during the late gestation. This happens as a result of the inability of the pregnant animal to maintain an adequate energy balance for the fast-growing maternalfetal unit. The clinical analysis of individual does often show elevated ketone body levels in urine and blood as well as hypoglycemia. Hypoglycemia is not a consistent finding,

Address for correspondence:

Dr. Surapaneni Krishna Mohan, Department of Biochemistry, Chettinad Hospital and Research Institute, Chettinad Academy of Research and Education (CARE), Rajiv Gandhi Salai (OMR), Kelambakkam, Chennai - 603 103, Tamil Nadu, India.

E-mail: krishnamohan.surapaneni@gmail.com

Received: $25-11-2018$

Revised: $19-12-2018$

Accepted: 26-12-2018 
with up to $40 \%$ of cases having normal glucose levels and up to $20 \%$ having hyperglycemia.

While clinical pregnancy toxemia in ruminants is relatively well studied, there is a paucity of information regarding metabolic changes in the subclinical form of the disease, especially in does. So far, very little work has been done on subclinical pregnancy toxemia in Malabari does. Occurrence of this ailment is worldwide and due to the importance of goat in the agrarian economy of the country, this disease drives the researchers to explore more on its subclinical stage since the treatment for pregnancy toxemia is often unsuccessful. Detection of subclinical condition helps to take necessary preventive measures that can be readily achieved by nutritional means and is far more rewarding than treatment. Therefore, the current study is aimed at screening of the Malabari pregnant does for subclinical stage of pregnancy toxemia and assessment of the difference in blood glucose concentration.

\section{MATERIALS AND METHODS}

\section{Experimental Animals}

The study was carried out in clinically healthy Malabari does maintained at the University Goat and Sheep farm, College of Veterinary and Animal Sciences (CVAS), Mannuthy, Thrissur, between July and September. Investigations were done in four groups of Malabari does, Group I early pregnant does (40-60 days), Group II late pregnant does with one fetus (110-150 days), Group III late pregnant does with two fetuses (110-150 days), and Group IV nonpregnant does (sexually matured). The day of mating was considered as $1^{\text {st }}$ day of pregnancy. The pregnancy was confirmed by 3.5 Megahertz B-mode ultrasonography. Group I consisted of seven animals, Group II consisted of six animals, and Group III consisted of eight animals. Group IV with eight animals was taken as control group.

\section{Collection of Blood Samples}

Blood samples were collected from all the 29 does. Blood was drawn between 8.30 am and 9.30 am and before morning feeding, by jugular venipuncture using sterile needle. Approximately $3 \mathrm{ml}$ of blood was dispensed into a vial without anticoagulant, and $2 \mathrm{ml}$ blood was dispensed into an anticoagulant (sodium fluoride) coated vacutainer. The tubes for serum collection were allowed to clot at room temperature for $1 \mathrm{~h}$, and the clear sera were collected by centrifugation at $3000 \mathrm{rpm}$ for $10 \mathrm{~min}$. The blood collected with anticoagulant was centrifuged immediately at $3000 \mathrm{rpm}$ for $10 \mathrm{~min}$ and the separated plasma was used for further investigation. Beta-hydroxybutyrate (BHB) concentration was determined kinetically by enzymatic UV method, in RX Monza analyzer using RANBUT BHB kit. Glucose concentration was determined immediately after blood collection by glucose oxidase/peroxidase method (endpoint method) using glucose LS kit (Euro Diagnostic Systems Pvt., Ltd.).

\section{RESULTS AND DISCUSSION}

Ketone bodies are byproducts of excessive breakdown of body fat to compensate for the negative energy balance of the body. The serum BHB is the predominant circulating ketone body. ${ }^{[2]}$ The elevated BHB levels inhibit the hepatic gluconeogenesis, and thus further increase maternal hypoglycemia. ${ }^{[3]}$ Risk factors include multiple fetuses, poor quality of ingested energy, decreased dietary energy level, genetic factors, obesity, lack of good body condition or high parasite load, and lack of exercise and do carrying multiple pregnancies. ${ }^{[4]}$

It has been reported in literature that crossbred ewes carrying multiple pregnancies are much more likely to experience ketosis. ${ }^{[5]}$ Anoushepour et al. have chosen the cutoff point of $0.8 \mathrm{mmol} / \mathrm{L}$ serum BHB level to detect the subclinical stage of pregnancy toxemia, and hence in this study, the same cutoff point was chosen. ${ }^{[6]}$ In the present study, a significant increase $(P<0.01)$ in serum BHB concentration was found in Groups I and II when compared with nonpregnant control group [Figure 1]. Group III formed of late pregnant does with two fetuses showed a highly significant increase $(P<0.01)$ when compared to control group. The mean BHB values were $0.45 \pm 0.01,0.59 \pm 0.01,0.81 \pm 0.10$, and $0.29 \pm 0.02 \mathrm{mmol} / \mathrm{L}$, respectively, for Group I, Group II, Group III, and control group. The results of this study showed that Group III formed of late pregnant does with two fetuses, in subclinical pregnancy toxemic stage. Pregnancy toxemia is a multifactorial disorder of energy metabolism; hence, so many factors other than the plane of nutrition can lead to this condition. The intense genetic breeding for twinning can be a momentous reason and, in addition, sudden feed change, transportation, and weather change can act as a precipitating cause of pregnancy toxemia. Since Malabari goat breed is well adapted to the hot and humid weather condition prevailing in the state, the stress due to the climate can be excluded and this may be a rationale behind subclinical condition not progressing to a clinically exhibiting

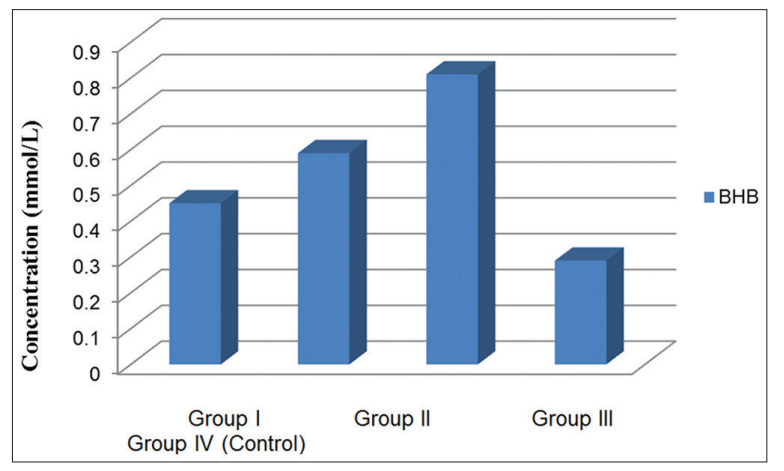

Figure 1: Concentration of beta-hydroxybutyrate $(\mathrm{mmol} / \mathrm{L})$ in different groups of Malabari does 


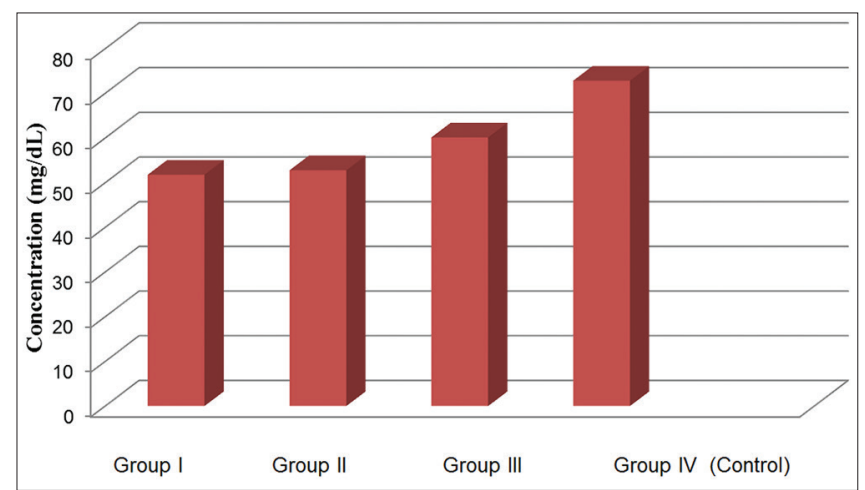

Figure 2: Concentration of glucose $(\mathrm{mg} / \mathrm{dL})$ in different groups of Malabari does

condition. From this, it was inferred that the regulatory and metabolic stress in late gestating does bearing twins was disproportionately high. Hence, further studies to assess the glycaemic status of animals were carried out to know more about the etiopathology of the disease. Ruminants appear to be well adapted to a carbohydrate economy based on their ability of gluconeogenesis. ${ }^{[7]}$ During pregnancy the glucose demand increases, as fetal demands for glucose are high, and the placenta can transport glucose from maternal to fetal plasma. ${ }^{[8]}$ When an imbalance occurs between the maternal ability to synthesize or absorb glucose and fetal consumption, hypoglycemia results. Significantly greater hypoglycemic responses in twin pregnancies than in singleton pregnancies have been reported to occur in sheep. ${ }^{[9]}$ In the present study, a highly significant decrease $(P<0.01)$ in plasma glucose concentration was found in Group I, Group II, and Group III when compared with control group [Figure 2]. The mean values obtained for glucose were $40.04 \pm 4.40$, $44.17 \pm 4.46$, and $46.08 \pm 3.04 \mathrm{mg} / \mathrm{dL}$ for Group I, Group II, and Group III, respectively, and that of control group was $62.54 \pm 4.36 \mathrm{mg} / \mathrm{dL}$. This findings were in accordance with Schlumbohm and Harmeyer ${ }^{[10]}$ and Anoushepour et al. ${ }^{[6]}$ The treatment for pregnancy toxemia is frequently unsuccessful, but detection of subclinical condition helps to take necessary prevention measures and that can be readily achieved by nutritional means and is far more rewarding than therapy.

\section{CONCLUSION}

By virtue of this present study, it is evident that hyperketonemia not only represents a disease sign but rather also acts in a multifunctional way in promoting the development of pregnancy toxemia. The reduced ability of the late gestating multiparous does to utilize ketone bodies seems to play a key role in the pathogenesis of this metabolic disorder. The treatment for pregnancy toxemia is frequently unsuccessful, but detection of subclinical condition helps to take necessary prevention measures and that can be readily achieved by nutritional means and is far more rewarding than therapy.

\section{ACKNOWLEDGMENTS}

The authors would like to thank Dr. R. Thirupathy Venkatachalapathy, Assistant Professor, Department of Animal Genetics, Breeding, and Biostatistics and all the faculties in the Department of Veterinary Biochemistry, CVAS, for their immense support.

\section{REFERENCES}

1. Alex R, Raghavan KC. Selection indices for genetic improvement of Malabari goats. Indian Vet $\mathrm{J}$ 2012;89:21-4.

2. Moghaddam GH, Hassanpour A. Comparison of blood serum glucose, beta hydroxybutyric acid, blood urea nitrogen and calcium concentrations in pregnant and lambed ewes. J Anim Vet Adv 2008;7:308-11.

3. Schlumbohm C, Harmeyer J. Hyperketonemia impairs glucose metabolism in pregnant and nonpregnant ewes. J Dairy Sci 2004;87:350-8.

4. Rook JS. Pregnancy toxemia of ewes, does, and beef cows. Vet Clin North Am Food Anim Pract 2000;16:293-317, 6-7.

5. Olfati A, Moghaddam GH, Bakhtiari M. Diagnosis, treatment and prevention of pregnancy toxemia in ewes. Anim Sci Res 2013;1:1452-6.

6. Anoushepour A, Mottaghian P, Sakha M. The comparison of some biochemical parameters in hyperketonemic and normal ewes. Eur J Exp Biol 2014;4:83-7.

7. Kaneko JJ, Harvey JW, Bruss ML. Clinical Biochemistry of Domestic Animals. $6^{\text {th }}$ ed. San Diego: Academic Press; 2008. p. 916.

8. Warnes DM, Seamark RR, Ballard FJ. The appearance of gluconeogenesis at birth in sheep. Biochem J 1977; 162:627-34.

9. Reid RL, Hinks NT. Studies on the carbohydrate metabolism of sheep. The metabolism of glucose, free fatty acids, ketones, and amino acids in late pregnancy and lactation. Aust J Agric Res 1962;13:1112-23.

10. Schlumbohm C, Harmeyer J. Twin-pregnancy increases susceptibility of ewes to hypoglycaemic stress and pregnancy toxaemia. Res Vet Sci 2008;84:286-99.

Source of Support: Nil. Conflict of Interest: None declared. 